\title{
Thermal evolution of solid-liquid equilibria in the quaternary system: $\mathrm{NaBH}_{4}-\mathrm{NaBO}_{2}-\mathrm{NaOH}-\mathrm{H}_{2} \mathrm{O}$
}

\author{
T. Vilarinho-Franco ${ }^{1,2}$, A. Teyssier ${ }^{2}$, R. Tenu ${ }^{2}$, J. Delmas ${ }^{1}$, P. Capron ${ }^{1}$, J.J. Counioux ${ }^{2}$, and C. Goutaudier ${ }^{2}$ \\ ${ }^{1}$ Laboratoire LITEN-DTNM-LCSN, CEA - Commissariat à l'énergie atomique et aux énergies alternatives de Grenoble, 17 \\ Rue des Martyrs 38054 Grenoble cedex 9, France \\ ${ }^{2}$ Laboratoire Multimatériaux et Interfaces, Université Claude Bernard Lyon 1, UMR CNRS 5615, 69622 Villeurbanne cedex, \\ France
}

The rise of portable electronic devices, brings to the fore the crucial issues of power supply. The foreseeable evolution in functionalities and utilizations, as regards portable electronic devices, together with the introduction of novel electronic components, entail considerable changes in requirements, in terms of power consumption and autonomy [1]. A Hydrogen generator system by means of the hydrolysis of borohydrides is a promising technology for portable fuel cells [2-4]. To increase the energy density of this $\mathrm{H}_{2}$ generator system, the $\mathrm{NaBH}_{4}$ concentration has to be maximized. For this, one of the main challenges remains to increase the $\mathrm{NaBH}_{4}$ concentration of alkaline aqueous solution without drawbacks due to the by-products crystallization, $\mathrm{NaBO}_{2} . y \mathrm{H}_{2} \mathrm{O}$, with the pseudo hydration degree $y=0,1 / 3,2 / 3,2$ and 4 [5]. Sodium hydroxide is added to the solution to limit the self-decomposition of $\mathrm{NaBH}_{4}$, thus stabilizing the system. The ultimate goal of this work is to describe the thermal evolution of solid-liquid equilibria in the quaternary system $\mathrm{NaBH}_{4}-\mathrm{NaBO}_{2}-\mathrm{NaOH}-$ $\mathrm{H}_{2} \mathrm{O}$, which represents the mixture present during the hydrolysis reaction. To delimit the liquid single-phase domain in the quaternary system, an isopletic section has been defined considering a constant $\mathrm{NaOH}$ composition.

\section{References}

1. CEA - Commissariat à l'énergie atomique et aux énergies alternatives: The Hydrogen Pathway <http://www.cea.fr/var/cea/storage/static/gb/library/Clef s50/pdf/094a095marsacq-gb.pdf $>$ (accessed Oct 11, 2012)

2. J. Delmas, L. Laversenne, I. Rougeaux, P. Capron, A. Garron, S. Bennici, D. Świerczyński, A. Auroux, Int. J. of Hydrogen Energy 362145 (2011)

3. B.H. Liu, Z.P. Li, J. of Power Sources 187527 (2009)

4. Ç. Çakanyildirim, M. Gürü, Int. J. of Hydrogen Energy 334634 (2008)
5. J. Andrieux, L. Laversenne, O. Krol, R. Chiriac, Z. Bouajila, R. Tenu, J.J. Counioux, C. Goutaudier, Int. J. of Hydrogen Energy 375798 (2012) 